\title{
The Design of Electrode of Coal Roadway Advanced Detector
}

\author{
Y. Zhou \\ School of Mechanical Electronic \& Information Engineering \\ China University of Mining and Technology (Beijing) \\ Beijing, China \\ Y.M. Lv \\ School of Mechanical Electronic \& Information Engineering \\ China University of Mining and Technology (Beijing) \\ Beijing, China
}

\section{J.T. Zhang}

School of Mechanical Electronic \& Information Engineering China University of Mining and Technology (Beijing) Beijing, China

\author{
Z.M. Liu \\ School of Mechanical Electronic \& Information Engineering \\ China University of Mining and Technology (Beijing) \\ Beijing, China \\ X.G. Liu \\ School of Mechanical Electronic \& Information Engineering \\ China University of Mining and Technology (Beijing) \\ Beijing, China \\ M. Wu \\ School of Mechanical Electronic \& Information Engineering \\ China University of Mining and Technology (Beijing) \\ Beijing, China
}

roadway advanced detector which mainly comprises of a transmitting device and a receiving device.

As an important part of the detector, the electrode has a great influence on the formation of the electric field and detection accuracy. Common electrode currently used underground can't satisfy the requirements of our instrument. Therefore, a kind of electrode is designed in this paper. The electrode is consistent with the principle of Dynamic and Directional Electric Field Excitation Method. It can also meet the special environment of coal mine and form good electric field.

\section{ELECTRODE REQUIREMENTS TO THE GROUNDING RESISTANCE}

Analyzing the instrument requirements to electrode and the special environment of the coal mine, we got the original parameters of the electrode design and established an original parameters table as design reference.

According to the transmitting device requirements to electrode, the maximum voltage value through the emitter electrode, constraint electrode and grounding electrode is $100 \mathrm{~V}$, the maximum voltage value through the receiving electrode is $10 \mathrm{~V}$.According to the receiving device requirements to electrode, the maximum current value through the emitter electrode, constraint electrode and grounding electrode is $100 \mathrm{~mA}$, the maximum current value through the receiving electrode is very weak and its magnitude is between10-3 10-4mA.

In order to form a good electric field of emission current, the partial pressure of electrode must be small. The electrode is good conductor, its resistivity is at a level of $10-8 \Omega \cdot \mathrm{m}$. For the electrode dimensions are in $\mathrm{cm}$ level, we can get the magnitude 
of electrode resistance should be between 10-3 10-4 $\Omega$, the magnitude of electrode pressure drop is between 10-5 10-4V at the maximum current value of $100 \mathrm{~mA}$. So the influence on the measurement results could be neglectful. According to the requirements of transmitting device, the magnitude of grounding resistance is at a level of $10 \mathrm{~K}$ through the theoretical calculation, so the real value of grounding resistance is less than it.

Based on the above analysis, establish the original parameter table of the electrode design in the following Table 1.

TABLE I. THEORIGINAL PARAMETER TABLE OF THE ELECTRODE DESIGN.

\begin{tabular}{|c|c|c|c|c|}
\hline & Emitterelectrode & Constraintelectrode & Grounding electrode & Receiving electrode \\
\hline Maximum voltage $(\mathrm{V})$ & 100 & 100 & 100 & 10 \\
\hline Maximum current(mV) & 100 & 100 & 100 & $10^{-3} \sim 10^{-4}$ \\
\hline Electrode resistance $(\Omega)$ & $10^{-3} \sim 10^{-4}$ & $10^{-3} \sim 10^{-4}$ & $10^{-3} \sim 10^{-4}$ & $10^{-3} \sim 10^{-4}$ \\
\hline 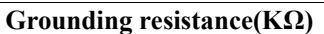 & $<10$ & $<10$ & $<10$ & $<10$ \\
\hline
\end{tabular}

\section{ELECTRODE DESIGN}

In the measurements of electrical prospecting, leakage detection, lightning detection, soil resistivity test, all need grounding the electrode, electrode grounding will inevitably produce grounding resistance $[3,4,5]$. The value of grounding resistance will have effects on the measurement results which can't be ignored $[6,7]$. If the grounding resistance is small, it can save power, improve the accuracy, enhance anti-interference ability of the system, work effectively and ensure the security of system. Therefore, reducing electrode grounding resistance is a major consideration in design of electrode. Electrodes used at present are usually of cylindrical stick shape and made of steel, it's the basis of the design.

Access to information, calculate the grounding resistance according to the definition of conductor resistance. In the practical application, in order to operate conveniently and guarantee the electrode have a good contact with the surrounding rock, cylindrical stick electrodes are always used, as shown in Figure I. In the figure, $\rho$ represents the resistivity of rock and assume the rock is a kind of infinite homogeneous isotropic medium here, the stick electrode has a radius of $\mathrm{r} 0$ and 1 represents the depth into rock.

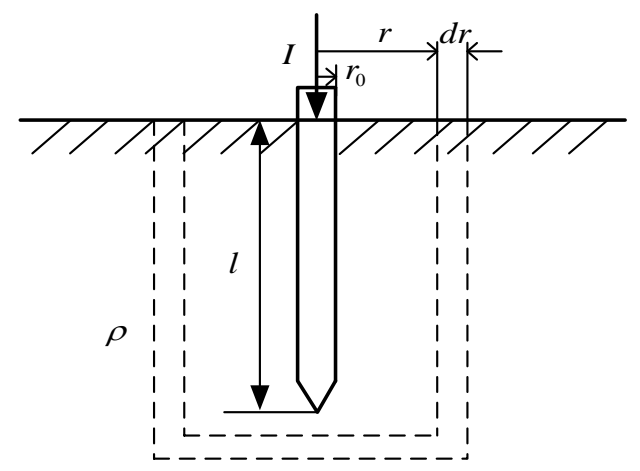

FIGURE I. THE PRACTICAL APPLICATION MODEL OF ELECTRODE.

$R_{1}$ represents the resistance from superficial layer $r_{0}$ of the electrode to a cylindrical layer with a radius of $r$, calculated as following:

$$
R_{1}=\int_{r_{0}}^{r} \frac{\rho d r}{2 \pi r\left(l+r-r_{0}\right)+\pi r^{2}} d R=\frac{\rho}{2 \pi\left(l-r_{0}\right)} \ln \frac{r\left(r_{0}+2 l\right)}{r_{0}\left(3 r+2 l-2 r_{0}\right)}
$$

When $r \rightarrow \infty$, the theory value of grounding resistance as following:

$$
R=\frac{\rho}{2 \pi\left(l-r_{0}\right)} \ln \frac{r_{0}+2 l}{3 r_{0}}
$$

(1) Determination of the electrode radius

Analyze the function relationship, the relationship between the grounding resistance $R$ and the radius $r_{0}$ of stick electrode is as following: the grounding resistance $R$ markedly decreases with the increase of stick electrode radius $r_{0}$. Therefore, in the actual measurement, the radius $r_{0}$ of electrode should be large as far as possible if condition permission. After full consideration of the factors such as handling, installation and demolition, choose the length of $0.5 \mathrm{~cm}$ as the radius of electrode.

(2) Determination the length of the electrode and the depth into rock

The surrounding rocks of coal mine are complex and majority of them are shale, argillaceous shale and sandstone shale. Assume the main component is shale, according to the information provided, the resistivity of shale is $5 \times 103 \Omega \cdot \mathrm{m}$.

By the resistivity of shale is $5 \times 103 \Omega \cdot \mathrm{m}$, the radius of electrode is $0.5 \mathrm{~cm}$, according to the formula (2), the relationship between grounding resistance $\mathrm{R}$ with the depth into rocklis shown in Figure II. From the figure we can see the grounding resistance increases with the decrease of the depth into rock, when the depth is more than $50 \mathrm{~cm}$, the curve flats gradually. Considering the larger the depth into rock, the more difficult wedging and pulling out the electrode, so the electrode length ranges of $50 \sim 70 \mathrm{~cm}$ and the depth into rock $35 \sim 50 \mathrm{~cm}$, select the depth into rock $35 \mathrm{~cm}$ here.

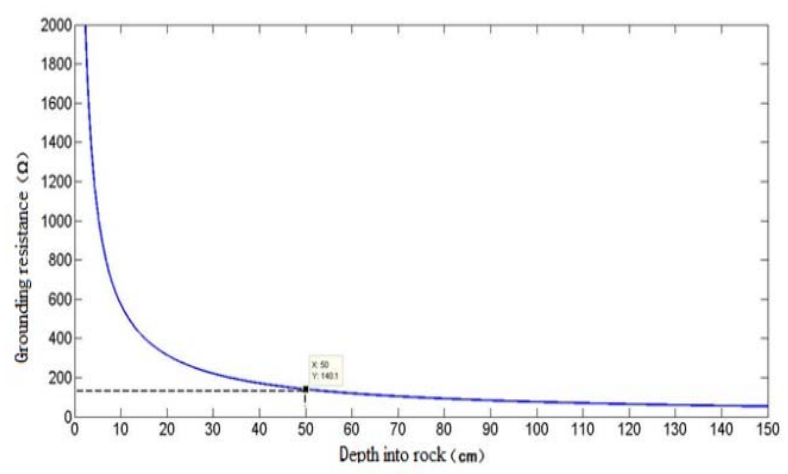

FIGURE II. THE RELATIONSHIP BETWEEN GROUNDING RESISTANCE WITH THEDEPTH INTO ROCK. 
Put determined parameter values into the formula (2), calculate the value of grounding resistance $\mathrm{R}=8.881 \times 103 \Omega$. Compared to the original parameter table, this value can satisfy the requirements of instrument, namely both the length of electrode and the depth into rock can meet the design requirements.

According to the depth into rock, combined with the length of exposed external electrode, the total length can be designed as $50 \mathrm{~cm}$, namely the length of depth into rock is $35 \mathrm{~cm}$ and the exposed part $15 \mathrm{~cm}$.

We test whether the resistance value can meet the requirements of the original parameter table after determining the basic sizes of electrode. Steel resistivity is variable due to the internal components, but all are good conductors. In approximate computation, the value can be replaced by the resistivity of iron which is the main component of it, namely $9.78 \times 10-8 \Omega \cdot \mathrm{m}$. The electrode resistance equals $1.56 \times$ $10-4 \Omega$ according to the property of resistance, which meets the resistance requirements of electrode in original parameter table. So the radius and total length of the electrode are designed reasonable.

\section{(3) Determination the taper of electrode head}

In order to install easily, we designed a taper of 1:3 on the electrode head. Because $3 \mathrm{~cm}$ is relatively small compared to total size, there is no significant impact to physical and chemical properties of electrode. Therefore, we assume the electrode is of ideal cylindrical in the above calculation.

(4) Integral structure of the electrode

Through the above design, schematic diagram of the integral electrode structure is shown in Figure III:

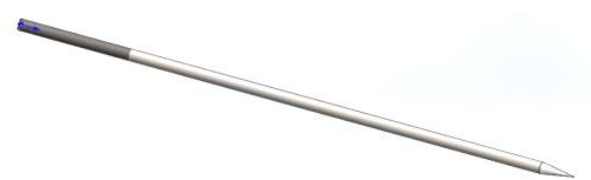

FIGURE III. SCHEMATIC DIAGRAM OF THE INTEGRAL ELECTRODE STRUCTURE.

\section{CONCLUSIONS}

In this paper, through the analysis of concrete requirements of the advanced detector, we design the electrode mainly take account of reducing the grounding resistance. With the help of simulation analysis by Matlab software, we get better theoretical value of basic parameters of electrode size and meet the requirements of the instrument.

\section{ACKNOWLEDGEMENTS}

This work was supported by the National High Technology Research and Development Program of China (863 Program) (No. 2012AA06A405) and the Fundamental Research Funds for the Central Universities (No.2010YJ01).

\section{REFERENCES}

[1] Liu Qingwen. The application of seismic prospecting technology during the development of gypsum mine [J]. Coal Geology \& Exploration, 2001, 29 (5): 60-62.

[2] Zhang Weijie. Research of advanced detection technology based on dynamic and directional electric field excitation method of coal roadway driving [D].China University of Mining andTechnology(Beijing), 2012.

[3] Fu Liangkui. Electrical exploration tutorial [M]. Beijing: Geological Publishing House, 1983.

[4] Guan Shaopeng, Pan Junfeng, NengChangxin, etc. Grounding resistance of electrode in landfill leakage detection using electrical method [J].Research of Environmental Sciences, 2008, 21 (6): 39-42.

[5] Mei Ji, Wang Yingbo, Sun Yanbing. Analysis of familiar questions about measuring of earth resistivity [J].Environmental Science \& Technology, 2011, 34 (6G): 246-248.

[6] Zhang Lingyun, Liu Hongfu, Li Chengyou. Experiment on ground resistance in high-density electrical measurement [J].Progress in Exploration Geophysics,2010, 33 (3): 179-183.

[7] Li-Hsiung Chen, Jiann-Fuh Chen, Tsorng-Juu Liang, and Wen-I Wang.A Study of Grounding Resistance Reduction Agent Using Granulated Blast Furnace Slag[J]. IEEE Transactionson Power Delivery, 2004, 19(3):973-978. 